\title{
THE IMPLEMENTATION OF CORPORATE SOCIAL RESPONSIBILITY INITIATIVE IN LITHUANIAN CONSTRUCTION SECTOR: SITUATION ANALYSIS
}

\author{
${ }^{1,2}$ Laima Okuneviciūte Neverauskiene, \\ ${ }^{2}$ Inga Pavlovska, \\ ${ }^{1}$ Miroslavas Pavlovskis \\ ${ }^{1}$ Lithuania, Vilnius, Vilnius Gediminas Technical University, \\ ${ }^{2}$ Lithuania, Vilnius, Lithuanian Social Research Centre
}

DOI: https://doi.org/10.31435/rsglobal_ijite/01062018/5671

\section{ARTICLE INFO}

Received 16 April 2018

Accepted 20 May 2018

Published 01 June 2018

\section{KEYWORDS}

corporate social

responsibility,

business,

construction sector,

assessment,

methodology,

guidelines on standards

\begin{abstract}
The article analyzes the concept of corporate social responsibility, its assessment methods, indicators and guidelines on standards. This work also presents the analysis of Lithuanian construction sector, examines the largest companies in this area, their possibility to develop the corporate social responsibility initiative, as well as the main difficulties in implementing the principles of social responsibility. The results show that in Lithuanian construction sector the highincome companies and companies that compete in the market over 15 years do not fully use the possibility of the development of global corporate social responsibility initiative.
\end{abstract}

(C) 2018 The Authors.

Введение. Актуальность темы. В современном обществе для компании, стремящейся успешно расширить свой бизнес, одной из главных целей является развитие социальной ответственности. Не может быть никаких сомнений в том, что успех долгосрочного бизнеса зависит от того, как компания может интегрироваться в окружающую среду. Таким образом в бизнес-среде все больше и больше рекомендуется применять концепцию корпоративной социальной ответственности, которая, как инструмент управления бизнесом, должна стимулировать компанию быть максимально прозрачной, беречь окружающую среду и сосредоточить внимание на общественное благосостояние.

Строительный сектор является одним из наиболее важных отраслей народного хозяйства, в которой представители бизнеса неохотно принимают концепцию корпоративной социальной ответственности. Развитию корпоративной социальной деятельности часто мешает узкое понимание менеджментом и акционерами КСО в качестве элемента благотворительности. Так как предприниматели не видят преимуществ от интеграции КСО в деятельности компании, они не хочет менять устоявшиеся процедуры реализируякорпоративного управления и инвестировать в развитие корпоративной социальной ответственности. Кроме того, в Литве, особенно в строительном секторе, наблюдается отсутствие хорошей деловой практики. Тем не менее, целесообразно поощрять эту концепцию, например, начиная от крупных, экономически сильных компаний, которые предоставляя конкурентоспособную продукцию и услуги в условиях меняющейся мировой экономики одновременно реализируя себя в социально ответственной деятельности. Следует подчеркнуть, что практика добросовестного и ответственного бизнеса должна быть основой национальной концепции экономики (Loosemore 2016; Герасимова 2016).

Цель статьи - оценить возможность интеграции принципов корпоративной социальной ответственности в деятельности Литовских строительных предприятий

Для достижения цели были сформулированы следующие задачи :

Представлять понятие корпоративной социальной ответственности, его сущность.

Изучить методы оценки социальной ответственности, показатели и стандарты.

Провести анализ строительного сектора Литвы. 
Оценить возможности Литовских строительных предприятий к инициативе КСО.

Для решения поставленных задач были использованы следующие методы исследования: анализ научной литературы, первичный и вторичный статистический анализ.

Для обработки и представления информации использованы методы кластеризации и визуализации.

Концепция корпоративной социальной ответственности. В литературе существует множество различных определений корпоративной социальной ответственности (КСО). Различные авторы часто выделяют различные аспекты: взаимоотношения на рабочем месте (как с сотрудниками, так и с деловыми партнерами и правительственными чиновниками), финансовые, экологические, этические проблемы. Также можно найти похожие или комплементарными определения КСО. Подводя итог вышесказанному можно сказать, что в научной литературе не существует единого мнения отображающего эту концепцию.

В научной литературе отмечается, что авторы КСО описывают как хорошее корпоративное управление, этичное и устойчивое управление а также некоторые добровольные обязательства, стремясь должным образом управлять своим воздействием на социальную сферу, окружающую среду и экономику, и, таким образом, и, таким образом, быть более полезным для общественности. Также отмечено что социально ответственные компании должны получать прибыль честно и этично, принимая во внимание не только потребности общества, но и регламентированных экономических, правовых и этических норм, которые применяются к предприятиям в определенный период времени. Следует отметить, что корпоративная социальная ответственность должна быть добровольным делом компании, которая принимает во внимание все сферы своей деятельности, согласовывает свои интересы с акционерами, сотрудниками, потребителями, сообществами, местными органами власти и другими заинтересованными сторонами, проводит экологическую политику направленную на предотвращение негативного воздействия хозяйственной деятельности на окружающую среду (Clegg, Bailey 2008; Grundey 2008; Desur 2013, Jha et al. 2016).

ГОСТ Р ИСО 26000 (Стандарт 2012) даёт следующую формулировку, понятию КСО:

социальная ответственность - ответственность организации за воздействие ее решений и деятельности на общество и окружающую среду через прозрачное и этичное поведение, которое:

содействует устойчивому развитию, включая здоровье и благосостояние общества;

учитывает ожидания заинтересованных сторон;

соответствует применяемому законодательству и согласуется с международными нормами поведения;

интегрировано в деятельность всей организации и применяется в ее взаимоотношениях.

В современном мире значение социальной ответственности довольно высоко, так как ее уровень влияет на уровень деловых отношений, уровень развития страны и качества жизни общества. Компании, которые могут продемонстрировать свои обязательства социальной ответственности, получают конкурентное преимущество, зарабатывая доверие всех заинтересованных сторон - клиентов, инвесторов, потребителей и местного сообщества (Skačkauskienė et al. 2016).

Обобщая результаты анализа научной литературы можно утверждать что КСО является стилем управления, который обязывает компанию к ведению открытого и прозрачного бизнеса, принимая во внимание проблемы общественности и защиты окружающей среды.

Методы оценки корпоративной социальной ответственности. Следует отметить, что в настоящее время не существует универсальной методики оценки социальной ответственности компании и соблюдения интересов заинтересованных сторон. Основной акцент делается, как правило, на сам факт принятия социальной ответственности или польза общественности.

Следует отметить, что в 2011 году в Литве была реализована методика оценки прогресса корпоративной социальной ответственности на на уровне страны, подготовленая на основе предложений международных экспертов (консалтинговые компании ACONA Ltd. и Daxam Sustainability Services). Основываясь на принципах данной методики определены 6 категорий показателей оценки прогресса компаний охватывающих основные области КСО. Каждая категория включает в себя ряд критериев оценки прогресса корпоративной социальной ответственности бизнеса (см. Таблицу 1).

В заключении можно сказать, что для исследования корпоративной социальной ответственности бизнеса существует много методов оценки. К сожалению, из-за различных культурных, правовых и экономических аспектов общей системы оценки не существует, так что в 
зависимости от отличительных особенностей рассматриваемых обстоятельств, подбирается лучший метод для оценки конкретной ситуации (Skačkauskienė и др. 2016).

Таблица 1. Критерии оценки прогресса корпоративной социальной ответственности бизнеса (Dubee et al. 2008; Graaf et al. 2010; Skačkauskienė et al. 2016)

\begin{tabular}{|c|c|c|}
\hline Nr. & Категория & Критерии \\
\hline \multirow{3}{*}{1} & \multirow{3}{*}{$\begin{array}{l}\text { Управление и } \\
\text { политика }\end{array}$} & $\begin{array}{c}\text { Утвержденная национальная стратегия в области устойчивого развития или } \\
\text { КСО }\end{array}$ \\
\hline & & Наличие органов государственной власти ведающих делами КСО \\
\hline & & Доля государственных зеленых закупок от общего объема закупок \\
\hline \multirow{4}{*}{2} & \multirow{4}{*}{$\begin{array}{c}\text { Обмен } \\
\text { информацией } \\
\text { и участие } \\
\text { заинтересованных } \\
\text { сторон }\end{array}$} & $\begin{array}{l}\text { Количество компаний присоединившихся к Глобальному договору ООН } \\
\text { (англ. United Nations Global Compact) }\end{array}$ \\
\hline & & $\begin{array}{c}\text { Процентная доля бизнес-ассоциаций осуществляющих отраслевую } \\
\text { деятельность в области КСО и устойчивого развития }\end{array}$ \\
\hline & & $\begin{array}{c}\text { Процентная доля компаний регулярно предоставляющих годовые отчеты, } \\
\text { которые охватывают вопросы устойчивого развития и КСО (из } 100 \text { крупнейших } \\
\text { по обороту) }\end{array}$ \\
\hline & & $\begin{array}{c}\text { Заявки на соискание Национальной премии в номинации "Социально } \\
\text { ответственный бизнес", за год }\end{array}$ \\
\hline \multirow[t]{2}{*}{3} & \multirow{2}{*}{$\begin{array}{c}\text { Гражданское } \\
\text { общество }\end{array}$} & $\begin{array}{c}\text { Процент высших учебных заведений предлагающих программы в области КСО } \\
\text { и устойчивого развития } \\
\end{array}$ \\
\hline & & Количество упоминания темы КСО в средствах массовой информации за год. \\
\hline \multirow{3}{*}{4} & \multirow{3}{*}{$\begin{array}{c}\text { Окружающая } \\
\text { среда }\end{array}$} & $\begin{array}{l}\text { Число компаний сертифицировавших свои системы экологического } \\
\text { менеджмента ISO 14001, EMAS }\end{array}$ \\
\hline & & $\begin{array}{c}\text { Потребление возобновляемых источников энергии и меры по } \\
\text { сокращению выбросов парниковых газов }\end{array}$ \\
\hline & & Экологические издержки. Оценка экологического следа \\
\hline \multirow{4}{*}{5} & \multirow{4}{*}{$\begin{array}{c}\text { Трудовые } \\
\text { отношения }\end{array}$} & $\begin{array}{l}\text { Число компаний сертифицированных в системе социально-трудовых } \\
\text { отношений SA8000, OHSAS } 18001\end{array}$ \\
\hline & & Доля работников, входящих в профсоюзы \\
\hline & & Гендерное равенство в бизнесе и управлени \\
\hline & & $\begin{array}{c}\text { Уровень производственного травматизма со смертельным исходом (на } 100000 \\
\text { работающих), человек. }\end{array}$ \\
\hline \multirow[t]{2}{*}{6} & \multirow{2}{*}{$\begin{array}{l}\text { Прозрачность } \\
\text { бизнеса }\end{array}$} & $\begin{array}{c}\text { Индекс восприятия коррупции (англ. Corruption Perceptions Index, CPI) } \\
\text { (Составляется международной неправительственной организацией } \\
\text { „Transparency International“) }\end{array}$ \\
\hline & & $\begin{array}{c}\text { Социально ответственное инвестирование (англ. (socially) responsible } \\
\text { investing; SRI) }\end{array}$ \\
\hline
\end{tabular}

Для того, чтобы оценить возможности развития КСО предприятий строительного сектора Литвы выделены наиболее подходящие для этого сектора показатели оценки социальной ответственности, которые могут быть интегрированы друг с другом с целью комплексной оценки возможностей корпоративной социальной ответственности сектора (см. Таблицу 2).

Таблица 2. Набор показателей для оценки социальной ответственности (Source: compiled by authors based on Dubee et al. 2008; Graaf et al. 2010)

\section{Количественные показатели:}

Количество компаний присоединившихся к Глобальному договору ООН (Global Compact Network)

1. Число компаний сертифицировавших свои системы экологического менеджмента ISO 14001, EMAS

2. Число компаний сертифицированных в системе социально-трудовых отношений SA8000, OHSAS 18001 Качественный показатель

3. Утвержденная стратегия в области устойчивого развития или КСО

Первый показатель представляющий, в процентах, долю компаний присоединившихся к Глобальному договору ООН в Литве является важным, поскольку демонстрирует уровень и развитие добровольного участия в международных сетях КСО. Глобальный договор ООН является самой большой в мире инициативой КСО, наблюдающей и содействующей участникам 
Глобального договора в социально ответственной деятельности на основе предоставленных докладов о ходе работы. Данный договор поддерживается топ-менеджментом компаний участников, и является стратегическим базисом для участников, чтобы добиться прогресса в области устойчивого развития и корпоративного гражданства.

Многие эксперты КСО рекомендуют чтобы первый шаг, который должна сделать компания, стремясь соответствовать КСО, это войти в одну или несколько специализированных Организаций Объединенных Наций, в том числе Глобального договора Организации Объединенных Наций (United Nations Global Compact) или Глобальной инициативы по отчетности (Global Reporting Initiative 2016).

В 2016 году в Литве насчитывалось 32 компании присоединившиеся к Глобальному договору ООН. Из них 19 процентов учебные заведения, 16 процентов - энергетика и водоснабжение, 25 процентов (то есть по 12,5 процента каждой) занимают компании, предоставляющие консультационные услуги, а также финансы и страхование. Фармацевтическая отрасль занимает 9 процентов, промышленность, коммерция и телекоммуникация - 19 процентов. (то есть по 6,33 процента каждой). Следует подчеркнуть, что строительных компаний в этом списке нет. Есть две промышленные компании, которые предоставляют свою продукцию для строительства и осуществляют монтаж, но они не причисляются к строительному сектору. Другим видам деятельностям (СМИ, транспорт, ИТ по 4 процента) - в общей сложности 12 процентов

Таким образом, анализ показывает, что наиболее глобальная инициатива корпоративной социальной ответственности применяться в области образования энергетики и водоснабжения, а также финансовых, страховых и консультационных услуг. Эта деятельность, как правило применяется только в больших предприятиях. Также было отмечено, что предприниматели строительного сектора не заинтересованы в добровольном вступлении в международные организации КСО.

По данным Глобального договора Организации Объединенных Наций в 2016 году, в мире из 12189 членов «Глобального договора» только 5,7\% (691) представляют компании относящиеся к строительному сектору и компании производители строительных материалов. Это еще раз подчеркивает, что строительный сектор медленно присоединиться к участникам Глобального договора.

Второй показатель - система экологического менеджмента (СЭМ) это глобальная мера потенциально применимая для любого типа и размера организации, которая стремится к совершенствованию механизма управления защиты окружающей среды и улучшению экологических показателей. Эта система имеет два основных стандарта, отвечающие определенным требованиям. ISO 14001, целью которого является отрегулировать деятельность компании в области охраны окружающей среды и EMAS, цель которого заключается в поощрении непрерывного улучшения экологических показателей.

ISO 14001 является международным стандартом, признанный во всем мире, который имеет четко определенные критерии сертификации и стандартизированное проведение независимого аудита. Этот стандарт предназначен для компании, которая направлена на внедрение, поддержание и улучшение системы управления защиты окружающей средой. Сертификат гарантирует что компания следует своей заявленной экологической политике, может воплотить требования и публично продемонстрировать соответствие критериям; обеспечить соблюдение природоохранного законодательства и нормативных актов, стремиться чтобы система экологического менеджмента была сертифицирована сторонней организацией.

На территории также Европейского Союза действует система EMAS - добровольное предписание, предъявлящее требования к систематизации ведения экологической работы и отчётности о ее выполнении. Эта система предназначена для всех компаний, работающих в Европейском союзе или в Европейской экономической зоне (Исландия, Лихтенштейн, Норвегия), которые хотят оценить, управлять и улучшить свою экологическую программу. Основное различие между ISO 14001 и EMAS заключается в том, что для EMAS требует от компании обязательной публикации отчетов и информации об экологическом состоянии промышленного объекта - оценка значительных экологических проблем, данные о выбросах загрязняющих веществ, образование отходов, сырье, потребление энергии и воды, уровень шума и т. д. (Franchetti 2011; Testa et al. 2014). Таким образом, эти стандарты помогают решать экологические проблемы страны и развивать сохранение экологического баланса, чем актуальны для социально ответственного бизнеса.

Третий показатель - система социально-трудовых отношений, включает стандарты SA8000 и OHSAS 18001. Стандарт для оценки социальных аспектов систем менеджмента SA8000 это сертифицированный стандарт, который может быть легко реализован, если соблюдается 
национальное и международное право. Цель стандарта SA 8000 - улучшение условий труда и жизненного уровня работников. В стандарте изложены требования к этической практике трудоустройства в соответствии с Конвенциями Международной организации труда, Всеобщей декларацией прав человека, конвенциями $\mathrm{OOH}$ и международными соглашениями. Компании, которые внедрили системы управления SA 8000 , не только улучшают свой имидж в обществе, но также влияют на лояльность и мотивацию сотрудников, что, в свою очередь, приводит к более качественной работе, позитивным изменениям в организациях и более эффективному управлению.

OHSAS 18001 Системы управления охраной труда и промышленной безопасностью (англ. Occupational Health and Safety Management Systems) является международным стандартом, который содержит требования и руководящие указания к разработке и внедрению систем менеджмента промышленной безопасности и охраны труда. Этот стандарт можно рассматривать как инструмент, который обеспечивает возможность компании управлять рисками, который определяет требования в системе управления охраной труда, позволяя компании разрабатывать и внедрять политику безопасности, устанавливать цели и процессы, предпринимать действия, необходимые для повышения эффективности системы и продемонстрировать, что они соответствуют юридическим обязательствам и требованиям стандарта. Стандарт помогает организациям обеспечить сокращение рисков для здоровья и безопасности работников при проделывании рутинной работы и избегать кризисных ситуаций (Fernandez-Muniz et al. 2012). Таким образом риски, понесенные каждой компанией, должны оцениваться, управляться и сводиться к минимуму с помощью выбора мер безопасности.

Четвертый показатель - утвержденная стратегия в области устойчивого развития или КСО. В XXI веке потребители стали более требовательными и прежде чем инвестировать или использовать товары их интересует социальные последствия деятельности организаций. Для инвесторов проблемы нефинансовых рисков становятся все более значимы, наряду с коммерческими и экономическими, поэтому отчеты по КСО становится неотъемлемой частью бизнес-стратегии (Костин 2014).

В 2010 г. был создан национальный комитет по мониторингу развития корпоративной социальной ответственности, который должен был обеспечить развитие корпоративной социальной ответственности и эффективное межведомственное сотрудничество. Также была реализована инициатива Национальной премия в номинации "Социально ответственный бизнес". В настоящее время вопросы КСО включены в правительственную программу, в которой подчеркивается корпоративная социальная ответственность бизнеса являются важнейшей предпосылкой устойчивого развития. Осуществление социальной ответственности должно обеспечиваться функциональной и эффективной системой правопорядка, которая предотвращает коррупцию и ее негативные последствия. Таким образом, подтверждается стратегическое значение принципов КСО для экономики Литвы (Skačkauskienė et al. 2016).

Общий анализ строительного сектора Литвы. Согласно данным Департамента статистики Литвы на 1 января 2016 года, в Литве насчитывалось 99200 действующих хозяйственных субъектов. По сравнению с 1 января 2015 года количество действующих хозяйствующих субъектов увеличилось на 6,6 процента, а в общей сложности с 2010 по 2016 год оно увеличилось на 19 процентов.

Как мы видим число действующих компаний с 2010 по 2016 год, быстро растет. Эта тенденция отражает тот факт, что экономика страны восстанавливается, и все больше людей не боятся рисковать и заниматься своим бизнесом. В то же время следует отметить, что наиболее активные компании в Литве работают в сфере торговли и ремонта. В течение анализируемого периода увеличилось число предприятий, работающих в сфере транспорта, образования, недвижимости. В это же время наблюдается сокращение числа предприятий в секторе производства, строительства и обслуживания (Рис.1). 


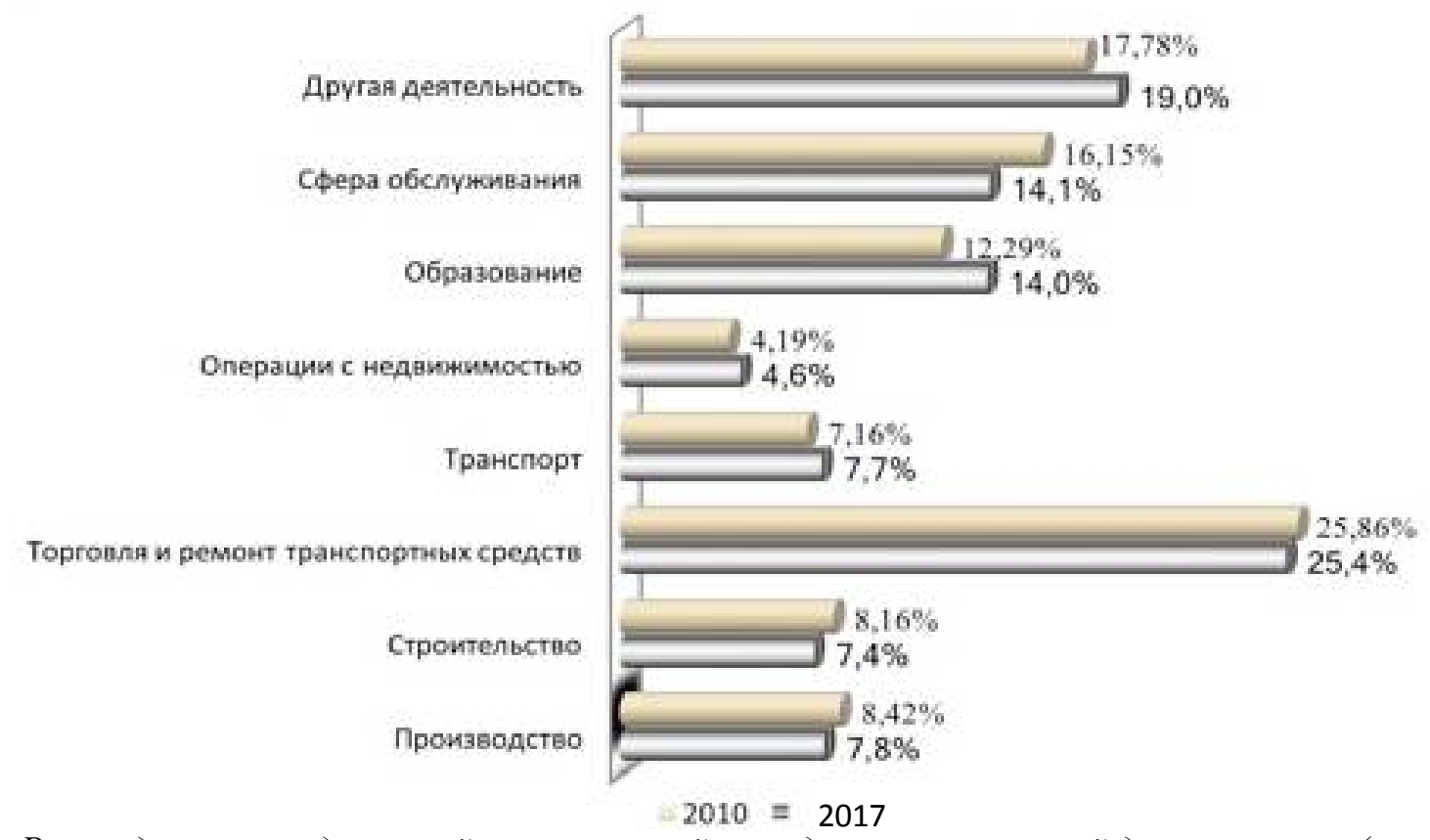

Рис. 1. Распределение предприятий и организаций по видам экономической деятельности (по данным Департамента статистики Литвы)

Несмотря на сокращение числа предприятий строительной отрасли в 2010-2016 годах, анализ статистических данных показывает, что оборот строительных работ ежегодно увеличивается (Рис. 2).

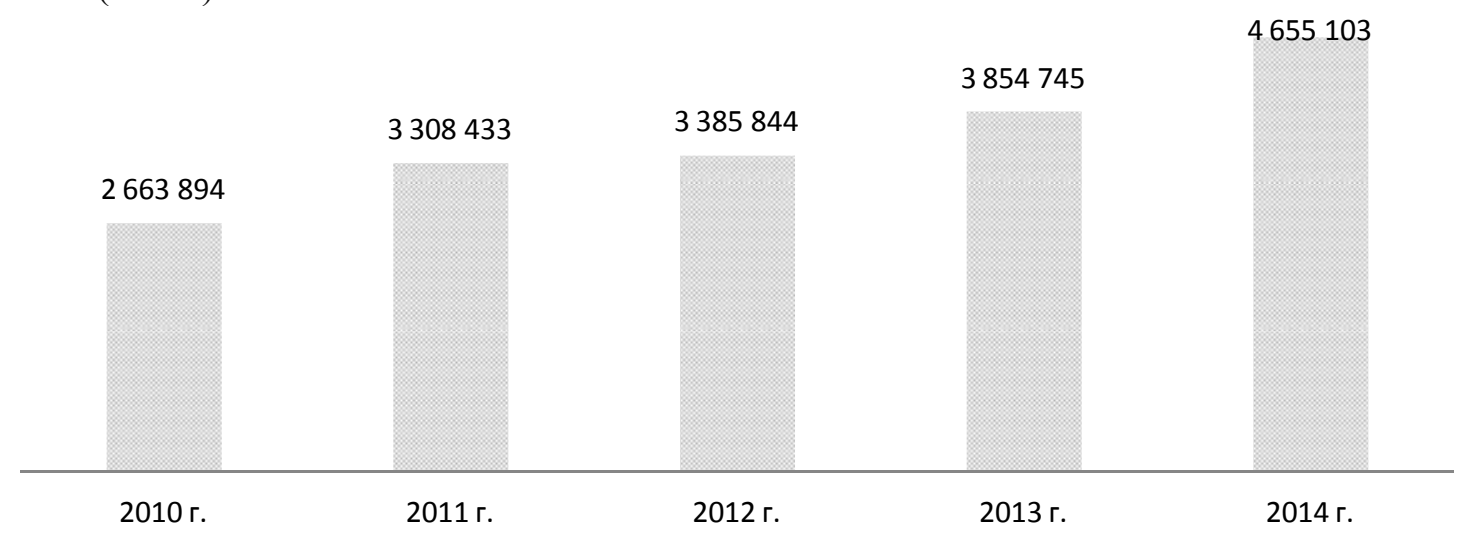

Рис. 2. Годовые обороты строительных работ в тыс. евро (по данным Департамента статистики Литвы)

Вклад литовского строительного сектора в национальную экономику отражается в ВВП, вырабатываемом всей Литвой, и составляет свыше 7,5\%. В Литве действуют 7309 строительных компаний, которые создают большое количество рабочих мест, что составляет примерно $9 \%$ всех работающих граждан Литвы. Кроме того с одним рабочим местом строительного сектора связаны 3-4 рабочих места в других секторах. Также важно отметить государственные закупки, стоимость которых в 2014 году составила 5,2 млрд. Евро, из которых $25 \%$ было потрачено на государственные закупки в строительном секторе (1,3 млрд. Евро).

Оценка компаний действующих в литовском строительном секторе. В условиях современного бизнеса очень важно знать как можно больше деталей о состоянии конкурента или партнера, чтобы понять текущую позицию компании на рынке и предвидеть ее конкурентные возможности в будущем. Основная цель каждой компании - получить прибыль. Прибыль имеет отношение ко всем показателям эффективности компании: доходы, расходы, активы, капитал, обязательства и т. д., а объём продаж - показывает способность компании получать прибыль от основной деятельности (Špicas 2013). 
Очевидно, что крупнейшие (согласно объему продаж) строительные компании в Литве работают эффективно и имеют ряд перспектив и различных возможностей, поэтому будут попрежнему именоваться лидерами литовского строительного сектора (Рис.3).

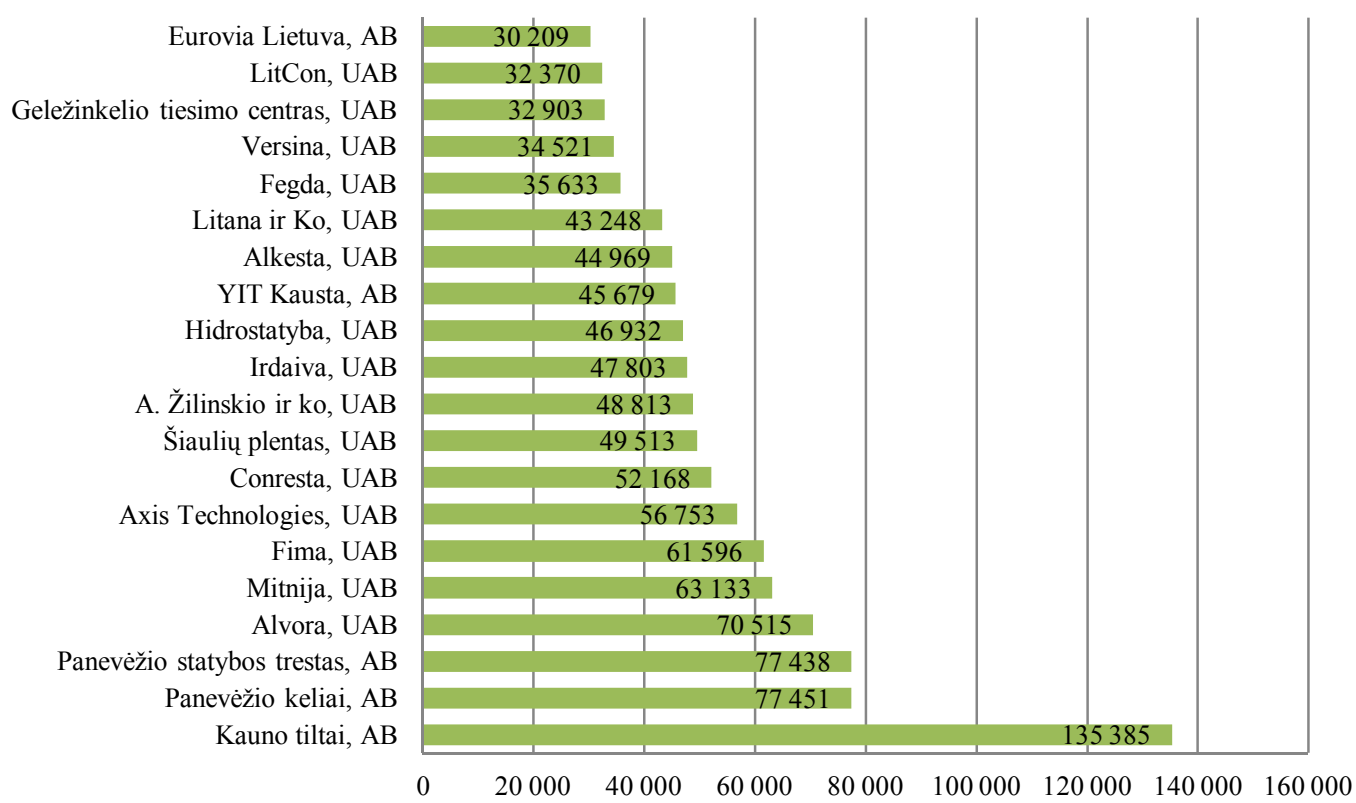

Рис. 3. Крупнейшие строительные компании в Литве согласно объему продаж в тыс. евро 2016 2. (по данным “Verslo žinios” 2017)

Продолжительность деятельности отражает количество лет которое компания существует на рынке. Все проанализированные компании давно работают в строительном секторе, сравнительно молодой организацией можно считать ЗАО «Irdaiva », которая конкурирует в строительном бизнесе 12 лет, а старейшей является АО «А. Žilinskis и Ко "- существует на рынке в течение 27 лет. Средний возраст предприятий составляет около 22 лет, а медиана - 24 года (Рис. 4).

Количество сотрудников отражает размер компании, то есть количество персонала, необходимого для решения задач компании. Почти у всех компаний более ста сотрудников, а половина компаний имеет более трехсот сотрудников. Это указывает на то что по масштабу рассматриваемые предприятия относятся к средним и крупным (Рис.5).

Почти все эти компании сертифицировали свои системы экологического менеджмента и охраны труда в соответствии с международными стандартами ISO14001 и OHSAS18001 демонстрируя что компании экологически безопасны и заботятся о безопасности своих сотрудников. И только несколько компаний проводят инициативу социальной ответственности практически поддерживая какую либо деятельность. Эти компании используют модель управления социальной ответственностью SA8000, которая обеспечивает благосостояние всех заинтересованных сторон, придает большое значение сотрудникам компании в соблюдении основных конвенций и директив по правам человека и предоставляет отчеты о корпоративной социальной ответственности. Отчет о корпоративной социальной ответственности демонстрирует, что мнения заинтересованных сторон были услышаны и учтены, и формирует долгосрочное доверие и сотрудничество. Эти отчеты показывают вклад компании в общество а также служит эффективным инструментом выявления, предупреждения и снижения нефинансовых рисков и формирования устойчивой репутации (как ответственного работодателя, партнера, гражданина и т.п.) (Костин 2014). 


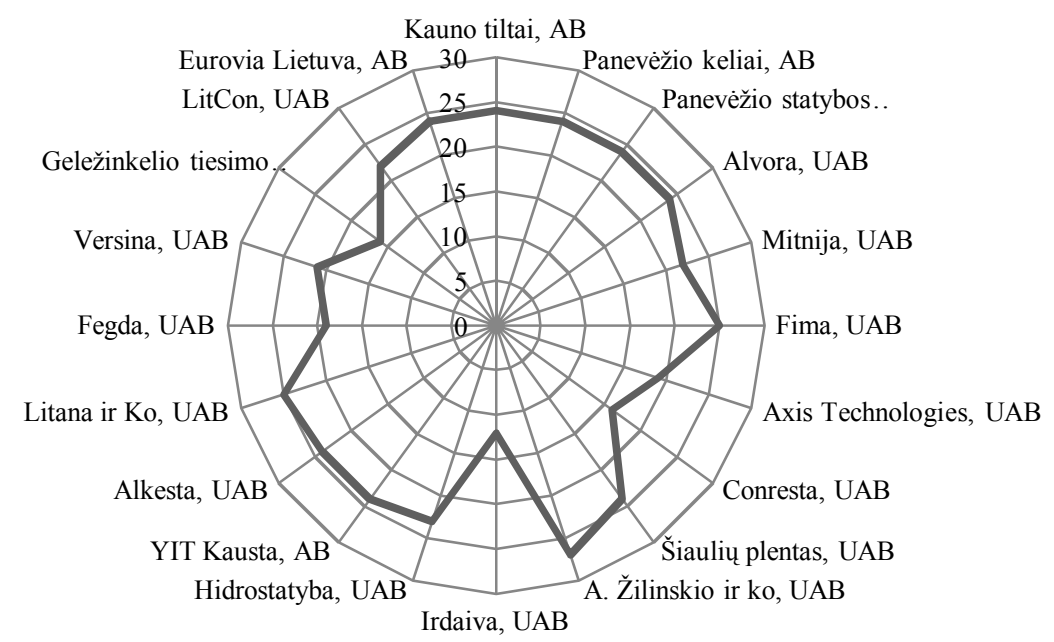

Рис. 4. Продолжительность деятельности крупнейших строительных компаний Литвы (по данныlм "Verslo žinios" 2017)

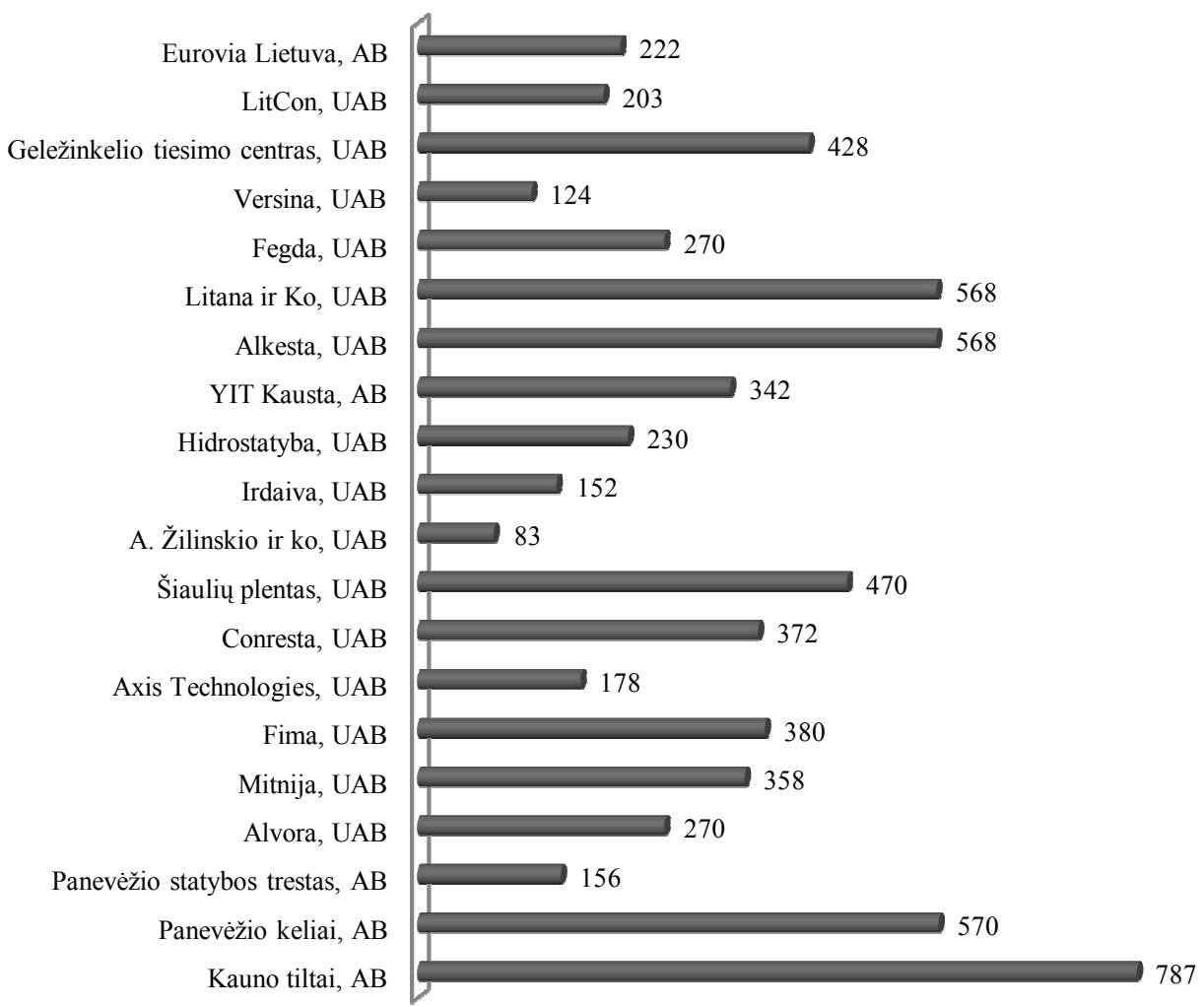

Рис. 5. Количество сотрудников в крупнейших строительных компаниях Литвы. (по данным "Verslo žinios" 2017)

Следует отметить, что, хотя все рассмотренные компании публикуют информацию о рабочих условиях, отношениях с сотрудниками, стандарт SA 8000, который показывает, что организация придерживается международных стандартов этики, имеет только 2 предприятия. Таким образом, можно предположить, что компании применяют стандарты основанные не на их деятельности и специфике а выбирают наиболее известные и широко используемые стандарты.

Основные проблемы строительного сектора в реализации принципов социальной ответственности. Являясь добровольной деятельностью компании, КСО отчетность и отчетность в области устойчивого развития представляют собой технологию и инструмент управления организацией, позволяющие систематизировать деятельность компании в нефинансовой сфере (социальные, экологические и иные программы и инициативы). Отчеты по 
КСО становятся все более значимы для потребителя, показывая и доказывая ему, что данная компания уделяет постоянное внимание экологическим и социальным аспектам в своей деятельности. Однако потребителям часто сложно использовать эту информацию при принятии решения о покупке. Обычные потребители редко ищут информацию о КСО, когда они рассматривают альтернативы, кроме того, в отчетах данные часто приводятся в довольно сложной форме, чтобы понять не будучи специалистом в этой области. (Костин 2014).

В строительном секторе критерий корпоративной социальной ответственности менее важен, чем другие критерии закупок, такие как цена, качество, марка, страна происхождения и т. д. Потребители склонны покупать социально ответственные продукты, которые не только не стоят дороже, но также не требует особых усилий по приобретению (Bray et al., 2011).

Loosemore (2016) выделил факторы КСО, которые отражают почему строительный сектор не склонен принять эту инициативу:

Отрицательное отношение к корпоративной социальной ответственности (отсутствие доверия, не серьезное отношение). Существует мнение, что социально ответственные предприятия занимаются благотворительностью и предоставляют услуги низкого качества. Сформировано представление что социально ответственные компании не могут работать с крупными проектами, и, как правило, получают небольшие, менее рискованные проекты.

КСО в строительной отрасли - это просто риторика, которая требует не результатов а исполнения требований.

Устойчивость к изменениям. Нежелание или неспособность изменять существующие цепочки поставок, практику государственных закупок, давно установленные методы найма, источники и связи. Область относительно жесткая, что затрудняет вхождение в существующие трудовые и конкурирующие сети.

Существующие методы закупок. Перечислены и без того сложные и бюрократические закупки / тендеры, к чему добавилась бы административная нагрузка на социально ответственные предприятия. Узкая концепция ценностей в строительном секторе (т. е. принцип наименьшей стоимости). Отсутствие опыта в социально ответственных закупках.

Отсутствие опыта социально ответственного бизнеса в строительном секторе. Вследствие этого плохое понимание и видение преимуществ, которые приносит социально ответственный бизнес. Новизна КСО концепции не известна / мало известна строительному сектору (рынку). Также негативно сказывается опыт клиентов столкнувшихся с социально ответственным бизнесом.

Строительный сектор четко регламентирован, поэтому КСО деятельность требует дополнительных усилий и затрат.

Культура строительной отрасли. В этой области преобладает коммерческое, твердое мышление, а КСО требует нематериальных активов, мягкости.

Компании занятие в строительном секторе не заинтересованы добровольно участвовать в международных сетях КСО. Представители этого бизнеса с трудом принимает инициативу КСО, хотя есть много дебатов по этой теме, но предприниматели страны не видит никаких преимуществ в этой инициативе. Как показывает проведенный анализ, до сих пор КСО распространялась только среди инновационных, конкурентоспособных или иностранных компаний в Литве.

Заключение. 1. В научной литературе концепция КСО интерпретируется по-разному, поэтому из определений мы можем понять, что КСО - это инструмент управления, который заставляет компанию действовать прозрачно, сохранять окружающую среду и ориентироваться на благосостояние общества.

2. Строительный сектор является одним из двигателей литовской экономики, способствующим благосостоянию страны. Он генерирует 7,5\% ВВП с большим количеством рабочих мест (около 9 \% всех сотрудников в Литве), что положительно влияет на рост занятости в других сферах деятельности. Поэтому строительство является экономически значимым сектором из-за его широкого профиля и связей с другими областями.

3. Рассмотрев крупнейшие строительные компании согласно объему продаж в Литве, можно сделать вывод о том, что глобальная инициатива по социальной ответственности бизнеса может быть инициирована компаниями с высоким доходом, которые находятся на рынке более 15 лет. Однако такие компании хотя и могут развивать эту инициативу, чаще всего только применяют наиболее известные и широко используемые стандарты. 


\section{ЛИТЕРАТУРА}

1. Bray, J.; Johns, N.; Kilburn, D. 2011. An exploratory study into the factors impeding ethical consumption, Journal of Business Ethics 98(4): 597-608.

2. Clegg, S.; Bailey, J. 2008. International encyclopedia of organization studies. Sage Publication 1:1-411. ISBN: 9781412956246.

3. Creditinfo. 2016. Stipriausi Lietuvoje [interaktiv], [2018-03-09]. Available from internet: http://creditinfo.lt/stipriausi-lietuvoje/

4. Dagiliene, L.; Leitoniene, S.; Grencikova, A. 2014. Increasing Business Transparency by Corporate Social Reporting: Development and Problems in Lithuania, Engineering Economics 25: 5461. ISSN:2029-5839.

5. Dubee, K.; Rugiero, J.D. 2008. Overview of CSR Performance Assessment Indicator Systems in the EU Member States and Advice on the Establishment of a CSR Indicator System in Lithuania. Daxam Sustainability Services.

6. Fernandez-Muniz, B.; Montes-Peon, J. M.; Vazquez-Ordas, C. J. 2012. Occupational risk management under the OHSAS 18001 standard: analysis of perceptions and attitudes of certified firms, Journal of Cleaner Production 24: 36-47.

7. Franchetti, M., 2011. ISO 14001 and solid waste generation rates in US manufacturing organizations: an analysis of relationship, Journal of Cleaner Production 19: 1104-1109.

8. Graaf, P.; Toennesen, Ch. 2010. CSR Self-Assessment Handbook for Companies. Vilnius: Baltijos kopija.

9. Grundey, D. 2008. Applying sustainability principles in the economy, Technological and Economic Development of Economy 14(2): 101-106.

10. Jha, B.K.; Singh, R., 2016. Corporate social responsibility in India, International Journal of Higner Education Research \& Development 1(1): 1-8. ISSN-2456-2629

11. Statistics Lithuania Database [interaktiv], [2018-03-19]. Available from internet: http://www.stat.gov.lt/

12. Loosemore, M., 2016, Social procurement in UK construction projects, International Journal of Project Management 34(2): 133-144. ISSN 0263-7863.

13. Ruževičius, J. 2015. The study of environmental management tools system, Economics and Management 14: 1084-1090. ISSN: 1822-6515.

14. Skačkauskienè, I.; Valentinovič, J. 2016. Apmokestinimo teisingumo ir socialinès atsakomybès Lietuvoje tyrimas, Mokslas - Lietuvos ateitis 8(2): 171-181. ISSN 2029-2341.

15. Špicas, R. 2013. Kredito rizikos vertinimo modelis Lietuvos kredito unijoms: santykiniu rodiklių ir jų analitiniu kriteriju parinkimas, Vadyba 1(22): 135-143. ISSN 1648-7974.

16. Testa, F.; Rizzi, F.; Daddi, T.; Gusmerotti, N. M.; Frey, M.; Iraldo, F. 2014. EMAS and ISO 14001: the differences in effectively improving environmental performance, Journal of Cleaner Production 68: 165-173.

17. United Nations Global Compact information [interaktiv], [2018-03-09]. Available from internet: https://www.unglobalcompact.org/what-is-c/participants/

18. Valstybinès mokesčių inspekcijos informacija [interaktiv], [2018-03-17]. Available from internet: https://www.vmi.lt/cms/mokesciu-moketoju-iregistravimas-pvm-moketoju-registre

19. Verslo žinios, 2017 [interaktiv], [2018-03-19]. Available from internet: http://www.vz.lt

20. Герасимова, С. А. (2016). Стратегический подход к корпоративной социальной ответственности в российских компаниях. Вестник Московской международной высшей школы бизнеса МИРБИС, 2(2), 123-129.

21. Костин, А. (2014). КСО и устойчивое развитие бизнеса в России. www. soc-eco. ru.

22. Стандарт ГОСТ Р ИСО 26000-2012: Руководство по социальной ответственности, 2012. 